\title{
Rapid growth rates of lion (Panthera leo) populations in small, fenced reserves in South Africa: a management dilemma
}

\author{
Susan M. Miller \& Paul J. Funston ${ }^{\ddagger}$ \\ Department of Nature Conservation, Tshwane University of Technology, Private Bag X680, Pretoria, 0001 South Africa \\ Received 26 November 2012. Accepted 9 October 2013
}

\begin{abstract}
Managers of reintroduced lion (Panthera leo) populations in small reserves $\left(<1000 \mathrm{~km}^{2}\right)$ in South Africa are challenged by high rates of population increase and how best to control them. We combined data from 14 small, fenced reserves to evaluate growth rate parameters and compared them to those in larger and/or open reserves. Growth rates of lions in small fenced reserves were only matched by those in Nairobi National Park (NP), which is relatively small and where the majority of the subadults emigrated away from the park. Initially, South African managers unconsciously mimicked this system by removing subadults to control population numbers, but increasingly chose euthanasia and hunting in the past decade, as the demand for wild lions for translocation decreased. They have, however, expressed a desire to use other methods of population control and mimic other open systems such as Kruger NP and Serengeti NP. Kruger NP had older ages of first reproduction and longer inter-birth intervals that could be mimicked through selective contraception. Alternatively, Serengeti NP had smaller litter sizes and lower cub survival, which could be mimicked through surgery to reduce litter sizes and, less attractively as it still involves lethal management and raises serious ethical concerns, selective culling of cubs. Mimicking Kruger NP may be more desirable as it is more ecologically similar to the small reserves than Serengeti NP. This understanding of the current situation, and how it could be altered to more closely mimic natural systems, will facilitate the development of a metapopulation-based management plan for lions in small reserves in South Africa.
\end{abstract}

Key words: growth rates, Panthera leo, re-introduction, small reserve management.

\section{INTRODUCTION}

In South Africa lions (Panthera leo) were extirpated from much of their historical range by the early 1900s (Nowell \& Jackson 1996). However, in recent decades lions have been reintroduced into over 40 small $\left(<1000 \mathrm{~km}^{2}\right)$, fenced areas, including private reserves, conservancies, protected areas, national and provincial parks, hereafter referred to as 'reserves' (reviewed by Funston 2008; Slotow \& Hunter 2009). These lion reintroductions have been successful on the individual reserve level; however, the introduced lions are all intensively managed (Hayward et al. 2007a; Hunter et al. 2007) and increasingly genetically compromised (Trinkel et al. 2008, 2010), the net effect of which reduces their conservation value on a regional scale (Slotow \& Hunter 2009). It has been suggested that small reserves in South Africa need to move away from intensive management in

\footnotetext{
*To whom correspondence should be addressed. Present address: Veterinary Genetics Laboratory, University of Pretoria, Private Bag X04, Ondersterpoort, 0110 South Africa. E-mail: dangerousfrizbee@gmail.com

${ }^{\ddagger}$ Present address: Senior Director: Lion Program, Panthera, 8 W. 40th Street, 18th Floor, New York, NY 10018, U.S.A
}

isolation towards a managed metapopulation approach (Funston 2008; Slotow \& Hunter 2009; Hayward \& Kerley 2009; Trinkel et al. 2010).

Lions have a complex social structure and as such present many challenges to managers. One of the major management challenges has been high reproductive and survival rates and the potential for overpopulation (Kilian 2003; Funston 2008; Lehmann et al. 2008; Kettles \& Slotow 2009; Slotow \& Hunter 2009). Previous studies of lion population growth in these reintroduced populations in South Africa have focused on lions in one small reserve at a time and often only for a few years immediately following introduction (Hunter 1988; Kilian 2003; Druce et al. 2004; Lehmann et al. 2008; Kettles \& Slotow 2009; Trinkel et al. 2010). Here, we collated time series data from 14 small reserves to quantify population parameters affecting growth rate and potential drivers of changes in these parameters. By comparing these data with the literature from more open systems, we explored the key drivers of high population growth rates in small reserves. This information will be used in collaboration with the Lion Manage- 
ment Forum (LiMF) to develop guidelines for management of lions in small reserves that mimic open systems (Miller et al. 2013) and will contribute to a Biodiversity Management Plan (BMP) commissioned by the South African government's Department of Environmental Affairs. Two open systems have been extensively studied over the past 40 years, Kruger National Park (NP) and Serengeti NP. Both ecosystems function in quite different ways and these will be explored as possible models for small reserve management.

\section{METHODS}

We sourced information to develop an up-to-date inventory of all reintroduced lion populations in South Africa (Fig. 1), including time series information. Historical records of 14 reserves were comprehensive enough for calculation of parameters affecting population growth and potential drivers of changes in these parameters.

General lion population characteristics were summarized for each reserve: area of reserve, year of reintroduction of lions, number of lions introduced per reserve, annual growth rates, number of lions at the end of the available data, first year perceived 'excess' lions occurred, number of 'excess' lions, and percentage of the population that these 'excess' lions represented. 'Excess' lions were defined as those lions that were removed by management through translocation, hunting or culling to maintain desired lion number for each reserve. Growth rate (or finite rate of increase $\lambda$ ) in year $t$ was calculated for each reserve using the following formula:

$$
\lambda_{\mathrm{t}}=N_{\mathrm{t}}+1 / N_{t} \text {, }
$$

where $N_{t}$ is the total lion population in the reserve in year $t$. The average and standard deviation of population growth rate for each year since introduction was calculated across all 14 reserves.

The natural population parameters identified as potentially contributing to growth rates were: age of first reproduction of females and males, interbirth intervals, litter size, sex ratio of litters, survival rates, immigration and emigration. For calculations involving the age of an animal, only those records accurate to one month were used, apart from survival of more than one year where data from records accurate to one year were added. The age of first reproduction for females was defined as the age when the first successful litter was born. Females that were older than 36 months when they were introduced were not included in this analysis as we did not know if they had had a litter prior to their relocation. The effects of male introduction, contraception and time since introduction on both the age of first reproduction and the inter-birth intervals were explored. The age of first reproduction for males was defined as the age when conception of the first litter occurred, assuming a gestation of 110 days (Skinner \& Chimimba 2005) and back calculating from the estimated date of birth. The ages were categorized into the number of lions in the coalition (one vs more than one) and the presence or absence of male competition on the reserve. Litter size was regarded as the number of cubs at first emergence from a den, usually a month or two after the birth. Natural and artificial immigration and emigration rates, methods (translocation, euthanasia and hunting) and ages were summarized across all reserves.

Potential drivers of growth rates identified were: lion density, contraception, tenure length, number of males in a coalition, time since new introductions of males, artificial immigration and emigration (through translocation, euthanasia and hunting). Annual lion density and number of excess lions were calculated based on reserve records. Chemical contraception was used sporadically by some reserves. The available data were compiled and the influence of the contraceptives on age of first reproduction and inter-birth intervals was determined. The length of male tenure was calculated based on the date of the first mating that produced a successful litter to the date when the animal was removed, died or a takeover occurred. The reason for the end of the tenure was determined based on reserve records. The removals of lions from an individual population were classified into: translocation, hunting, euthanasia, natural emigration (through the fence) and unknown.

Scatter plots were made to relate growth rate parameters with potential drivers of changes in these parameters. Linear regression was then performed, where possible, to determine if any of these drivers showed a correlation with any of the parameters. A summary of published data for open systems (Kruger NP, Serengeti NP and Nairobi NP) for the same parameters was compiled to use as a comparison to the small, fenced reserves.

\section{RESULTS}

\section{Summary of reintroductions and excess lions}

Lion reintroductions in South Africa started in 1991. By October 2011, 45 fenced reserves 




Fig. 1. Locations of reserves with re-introduced lion populations in South Africa. Grey circles indicate reserves with data used in this analysis; black circles, those without.

(Fig. 1) had free-ranging lion populations totalling approximately 700 lions. The rate of increase in the number of reserves that were reintroducing lions peaked from 2001 to 2005 with 17 new reserves during that time, and has declined in recent years to less than four per year (Fig. 2). The average number of lions in the first reintroduction was 6.0 (S.D. = 3.83), and the mode was four $(n=$ 39 reintroduction events). Table 1 summarizes the individual reserves' current lion numbers, with Madjuma Game Reserve (GR) and Karongwe Private Game Reserve (PGR) having only seven lions through to Hluhluwe-iMfolozi Park with about 200 lions (Grange et al. 2012).

Lion growth rates were highest in the years immediately following reintroduction and tended to stabilize thereafter (Fig. 3). For 12 of the reserves we were able to determine the first year that excess (by the managers' estimation) lions were removed. This ranged from two to five years (Table 1). The reserve with the lowest number of excess lions per year was Selati GR with an annual average of 0.16 excess lion (accounting for $1.7 \%$ of their lion population). The highest was Pilanesberg NP with 7.4 excess lions per year (or $14.7 \%$ of their lion population). The average number of excess lions across all reserves was 2.4 (or $12.6 \%$ of the overall population; Table 1).

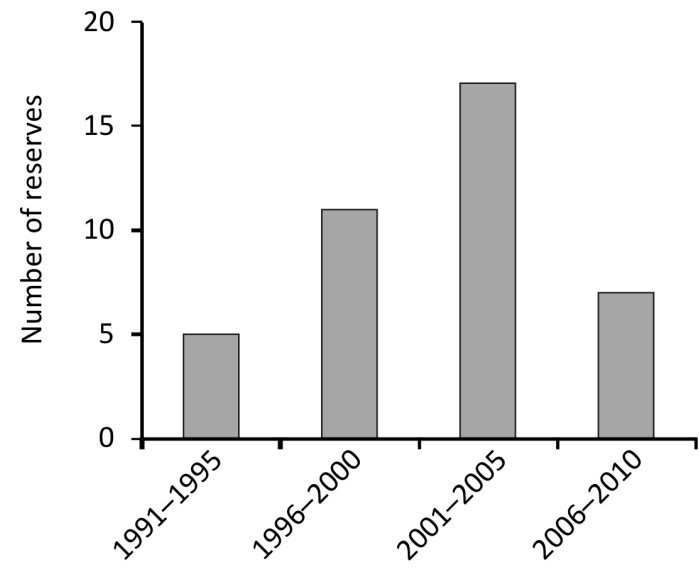

Fig. 2. Number of small reserves in South Africa where lions were reintroduced between 1991 and 2011.

\section{Female reproduction}

The average age of first reproduction for lionesses was 39.6 months (S.D. $=9.4$, range: 26 to 76 months, $n=61$ lionesses in 10 reserves; Table 2). Of the nine reserves studied, five had at least one female giving birth before the age of 36 months, accounting for $25(42 \%)$ of all lionesses studied. Of these 25 , six were newly introduced lionesses, four conceived shortly after a male 'takeover'/replacement (of which two were 
Table 1. Summary of lion population growth rates and the number of perceived 'excess' lions in small reserves in South Africa.

\begin{tabular}{|c|c|c|c|c|c|c|}
\hline Reserve & Intro year & Area $\left(\mathrm{km}^{2}\right)$ & No. lions ${ }^{1}$ & $\begin{array}{l}\text { First year with } \\
\text { excess lions }\end{array}$ & $\begin{array}{l}\text { Av. excess } \\
\text { lions/year }\end{array}$ & $\begin{array}{c}\% \text { of pop. in } \\
\text { excess }\end{array}$ \\
\hline Venetia-Limpopo NR & $\mathrm{n} / \mathrm{a}$ & 340 & 8 & - & 2.0 & 12.2 \\
\hline Thornybush NR ${ }^{2}$ & 1991 & 116 & 11 & - & 0.2 & - \\
\hline Mun-ya-wana PNR & 1992 & 246 & 33 & 4 & 5.0 & 17.9 \\
\hline Pilanesberg $\mathrm{NP}^{3}$ & 1994 & 570 & 45 & 2 & 7.4 & 14.7 \\
\hline Greater Makalali PGR & 1994 & 203 & 19 & 5 & 2.4 & 14.1 \\
\hline Madikwe $\mathrm{GR}^{3}$ & 1995 & 620 & 68 & 2 & 4.7 & 11.9 \\
\hline Mabula GR & 1997 & 16.5 & 7 & 3 & 1.6 & 18.7 \\
\hline Welgevonden PGR & 1998 & 330 & 15 & 5 & 2.0 & 10.3 \\
\hline Karongwe GR & 1999 & 79 & 7 & 2 & 1.3 & 16.2 \\
\hline Shamwari GR & 2000 & 139 & 23 & 3 & 2.3 & 15.6 \\
\hline Kwandwe PGR & 2001 & 185 & 20 & 2 & 2.6 & 17.4 \\
\hline \multicolumn{7}{|l|}{ Addo Elephant NP } \\
\hline Main Camp & 2003 & 241 & 9 & 4 & 1.2 & 10.8 \\
\hline Kuzuko & 2007 & 152 & $2^{4}$ & - & - & - \\
\hline Nyathi & 2011 & 140 & 3 & - & - & - \\
\hline Thanda PGR & 2004 & 70 & 11 & 3 & 0.62 & 8.1 \\
\hline Selati GR & 2005 & 285 & 13 & 3 & 0.16 & 1.7 \\
\hline Average & & & & 3 & 2.4 & 12.6 \\
\hline
\end{tabular}

${ }^{1}$ Most recent numbers available.

${ }^{2}$ Data available only since 2001.

${ }^{3}$ Data available only until May 2003.

${ }^{4}$ Males only.

Abbreviations: NR: Nature Reserve; PNR: Private Nature Reserve; PGR: Private Game Reserve. GR: Game Reserve; NP: National Park.

also newly introduced lionesses) and the other 17 were in 'established' prides (Fig. 4A). Two of the 61 lionesses in small reserves were contracepted before their first litter. One gave birth at 40 months, only 20 months after the treatment. The other one did not conceive until 76 months, 60 months after the treatment. Age of first reproduction did not correlate with the time since introduction, the time since males were introduced or any other factors tested (data not shown).

The average inter-birth interval, in the event of the previous litter having survived, was 26.0 months

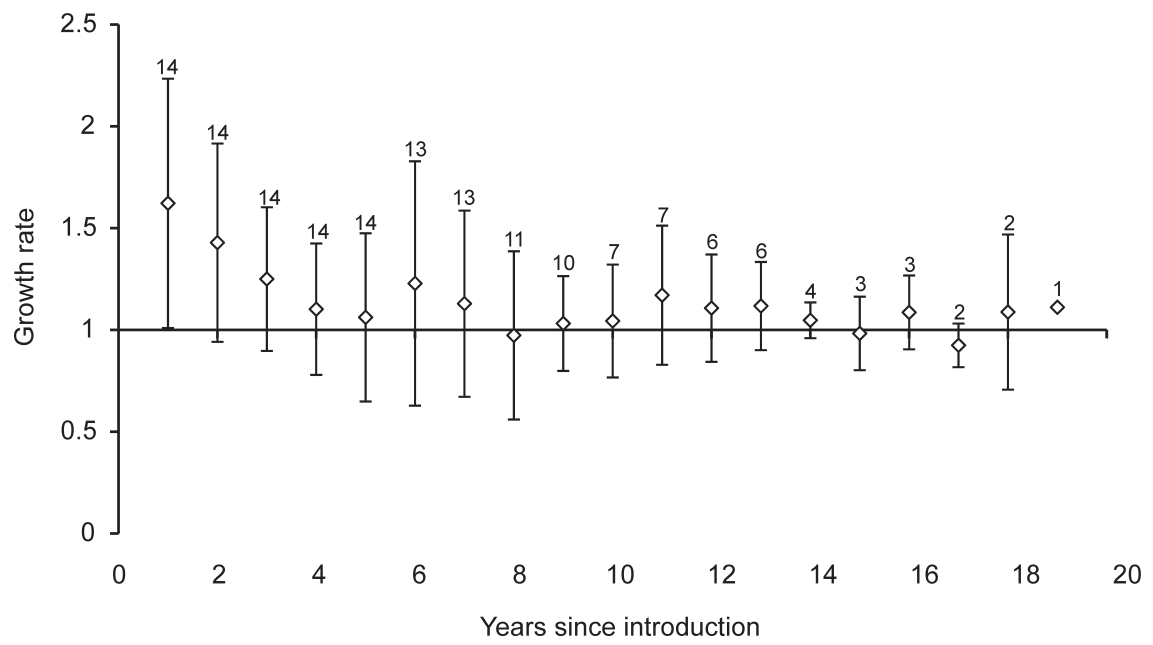

Fig. 3. Average annual lion population growth rate across 14 small reserves in South Africa. The error bars represent standard deviations. Since not all reserves have had lions for equal lengths of time, not all data points are based on averages of $n=14$; numbers above the data points indicate the number of reserves per point values. 
(S.D. = 13.6) with a range of 7 to 72 months ( $n=124$ inter-birth intervals of 58 lionesses on 11 reserves; Table 2). There were five cases where the inter-birth interval was below the average following takeover by new males (Fig. 4B). In one case infanticide was confirmed; in another it was suspected; in the third yearling cubs were kicked out of the pride and were presumed dead, and in the last two the previous litters were still alive (here the inter-birth intervals did, however, approach the average).

There were very limited data on contraception in small reserves. There were nine records of contraception being followed by birth of cubs at some time. In two cases the contraceptive did not appear to lengthen the inter-birth interval and the lionesses gave birth 18 and 23 months, respectively, after their previous litter (Fig. 4B), although in the case of the 23-month interval, the contraceptive was administered when the cubs were only five months old. In the other seven cases contraception extended the inter-birth interval to 34 months or more (Fig. 4B).

\section{Litter size and sex ratio}

The average litter size at emergence from a den was 3.0 (S.D. $=0.95)$ with a range of one to six ( $n=241$ litters from 99 lionesses on 13 reserves; Table 2). Figure $4 \mathrm{C}$ shows the distribution of litter sizes with three being the most common. Litter size did not correlate with lioness age, success of previous litter or any other factors tested (data not shown).

Of the 665 cubs observed, 328 were male, 287 were female and 66 were of unknown sex. There was no significant difference between the number of males and females $\left(\chi^{2}=2.733\right.$, d.f. $=1$, $P=0.098)$. When examined in more detail, sex ratio of litters did not correlate with lioness age, lion density or any other factors tested (data not shown).

\section{Male reproduction}

The range of ages at which male lions first secured tenure (based on the first successful conception) was 23 to 82 months with an average age of 45 months (S.D. $=12.6 ; n=49$ males in 32 coalitions on 10 reserves; Table 2). Of the 14 males that gained tenure before 39 months of age, nine of them were the only males on the reserve (either individually or in a coalition of like-aged lions), and five had competition from established males (Fig. 5A). There was no trend relating age of 

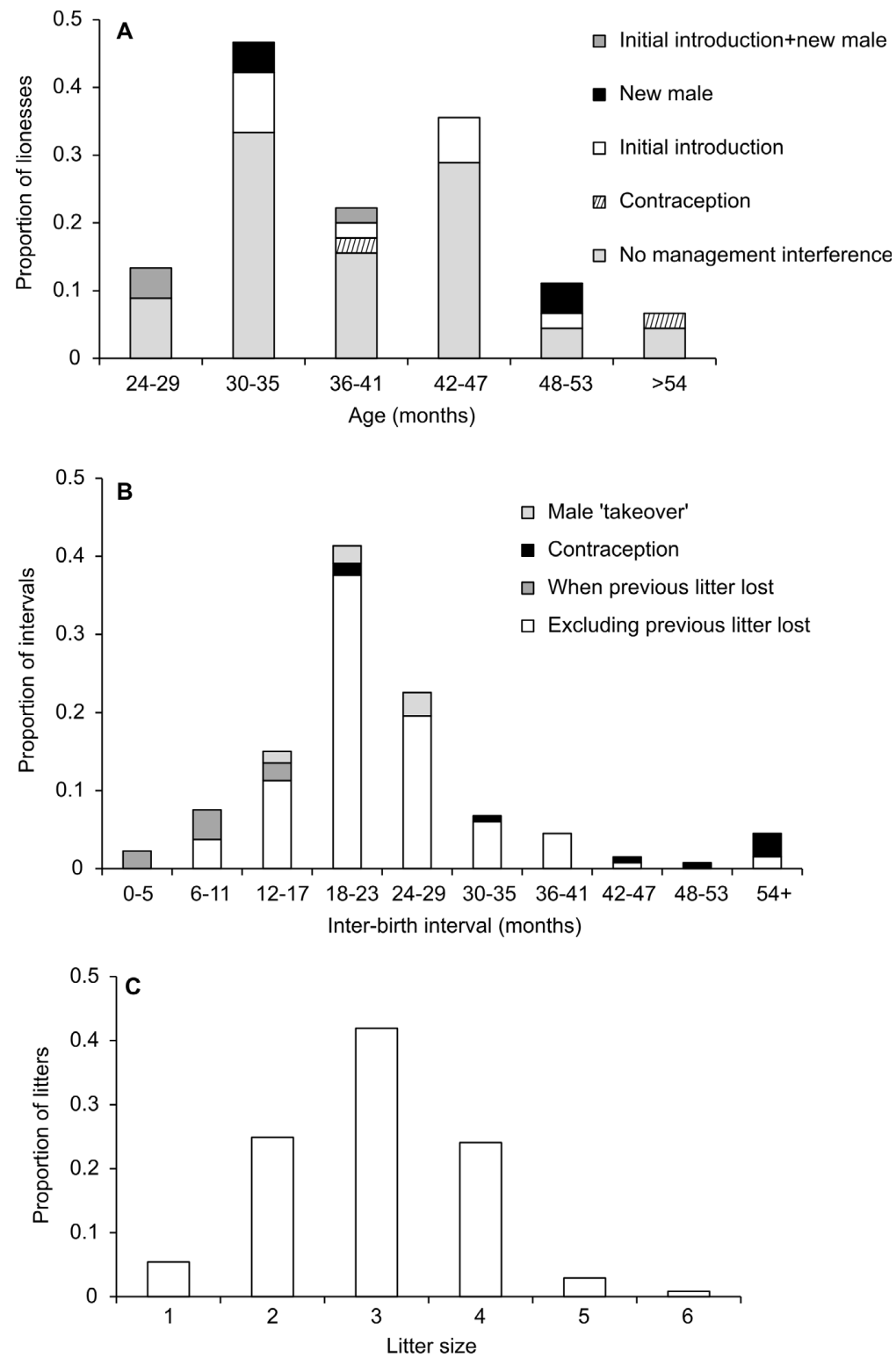

Fig. 4. Female reproduction in small reserves in South Africa. A, Age of first reproduction $(n=61$ lionesses in 10 reserves); B, inter-birth interval distribution ( $n=140$ inter-birth intervals of 62 lionesses in 12 reserves); C, litter size (at emergence) distribution ( $n=241$ litters from 99 lionesses in 13 reserves).

first reproduction to whether a lion was part of a coalition or not, or if there was competition on the reserve already (ANOVA, $F_{(3,45)}=0.85, P=0.47$ ).

\section{Male tenure length}

The length of male tenure ranged from four to over 132 months (the male in charge for 132 months was still in charge when the data were collected; $n=48$ males in 32 coalitions on 12 reserves;
Fig. 5B). The average length was 50.0 months (S.D. = 34.3). The various reasons for termination of male tenures are summarized in Fig. $5 \mathrm{C}$. The majority of these males were hunted $(35 \%)$. Only four takeovers occurred naturally $(0.9 \%)$, all others were induced by managers removing older males and introducing new ones. Most reserves removed subadult males before they became a threat to existing pride males. 

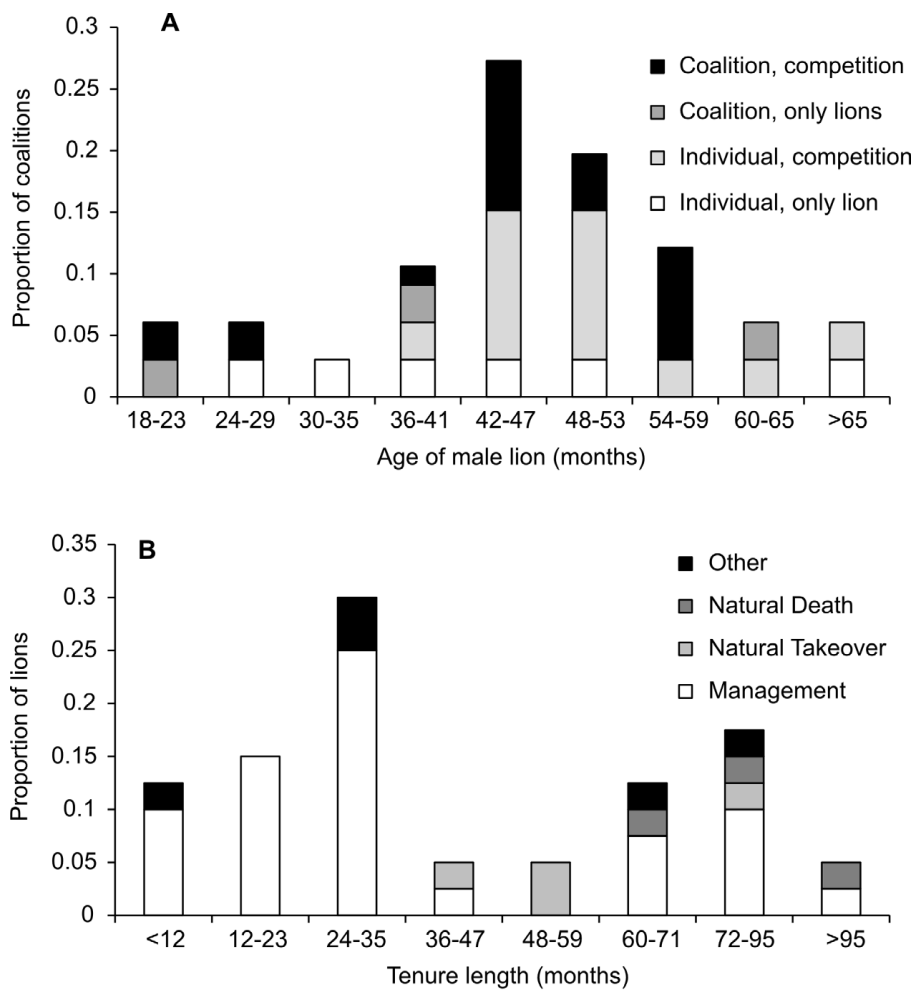

C

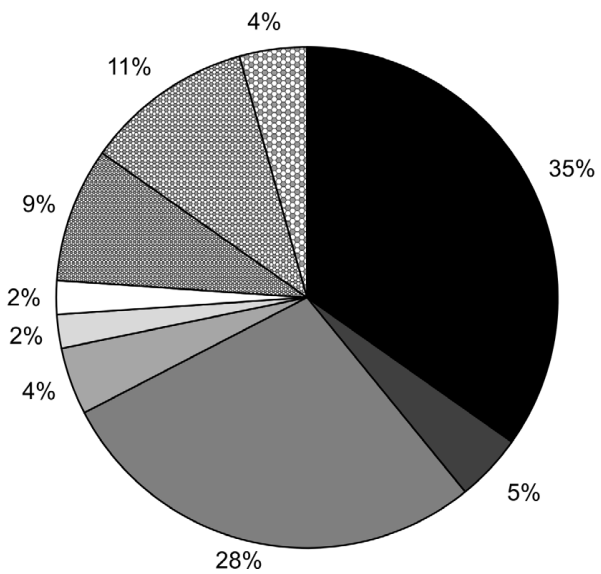

- Hunted

- Shot

口 Translocated

口 Snare

$\square$ Euth - medical

ㄷth - inbreeding

Died - not takeover

圈 Natural takeover

图 Disappeared - no takeover

Fig. 5. Male reproduction and tenure in small reserves in South Africa. A, Age of first reproduction of males ( $n=49$ males in 32 coalitions in 10 reserves); $\mathbf{B}$, length of the tenure and reason for its termination ( $n=48$ males in 32 coalitions in 12 reserves), 'Natural Death' refers to cases where the cause of death was unknown whereas 'Natural Takeover' refers to cases with evidence of a take-over by other males; $\mathbf{C}$, method of male tenure terminations $(n=51$ males in 35 coalitions in 13 reserves).

\section{Survival}

Cub survival to one year was $86.9 \%(n=605$ cubs in 13 reserves). Of the 79 cubs that died, 37 died of unknown causes, leaving 40 with known or suspected causes as follows: 14 infanticide and a further three litters (nine cubs estimated) suspected of infanticide, seven killed by other lions (not adult males), two abandoned, two died at birth, four were euthanased following the death of their mother, one euthanased (no reason given) and one died in a snare. Thus only five of the deaths were caused by man, the rest were natural. 


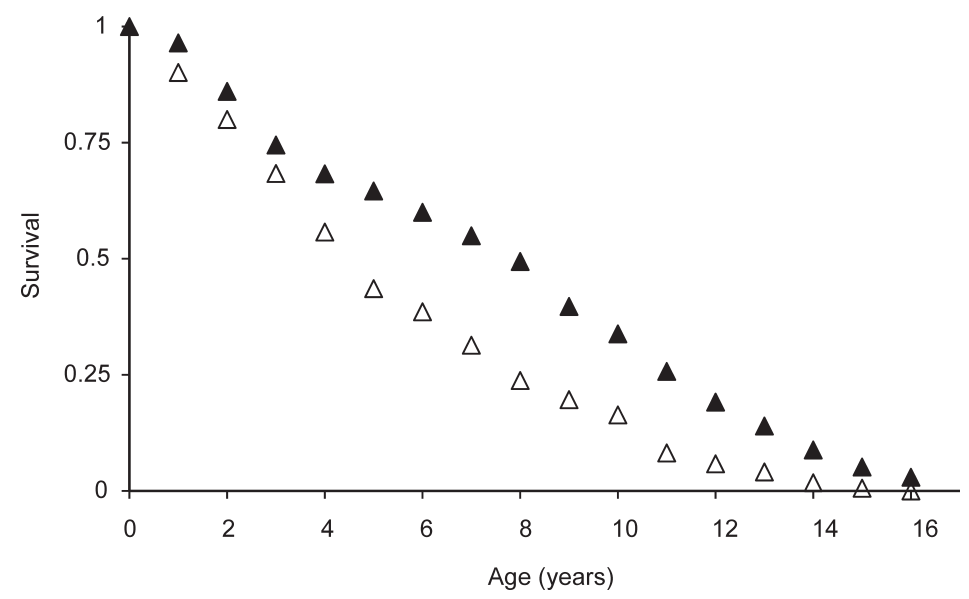

Fig. 6. Adult survival of lions in small reserves in South Africa from 13 reserves. Filled triangles represent females $(n=379)$, whereas open triangles represent males ( $n=415$ males).

While the most prominent cause was infanticide ( $45 \%$ of known causes), this was only recorded on two reserves (three times in Mun-ya-wana Private Nature Reserve (PNR) and four times in Pilanesberg NP) and suspected on one (Addo Elephant NP females were seen lactating three times and no cubs were ever seen; there was pressure from male lions and hyaenas in all cases). All but one incident happened when lions were still settling down after having been reintroduced.

Adult survival rates for males and females were similar for the first three years, after which females had a higher survival chance than males until 15 years of age (Fig. 6). Females had a higher survival rate than males $\chi^{2}=68.984$, d.f. $=13$, $P<0.001)$ starting from four years of age.

\section{Immigration and emigration}

Natural immigration was almost non-existent in small reserves. One male entered Greater Makalali PGR in 2000 and left again a month later, and three males entered Selati GR and were hunted. Occasional vagrant males have been seen on DeBeers Venetia-Limpopo Nature Reserve (NR) over the years; and at least one stayed and established a territory. Six reserves added new males through translocation, usually with existing males being removed (to simulate a takeover and reduce inbreeding). These males accounted for 20 lion translocations onto six reserves. No reserve in our dataset added females to supplement the population following initial introductions. Thus in general after the initial introduction phase, minimal natural or induced immigration occurred.

Natural emigration has also been almost non-existent. One lioness on DeBeers VenetiaLimpopo NR left the reserve, and then spent part of her time on DeBeers Venetia-Limpopo NR and part on neighbouring farmlands before being hunted. Two sets of two, 3-year-old males left Thornybush GR, which borders other reserves and Kruger NP. Several reserves have had lions breakout and have relocated them back to the reserve and a few have died of injuries trying to breakout (anecdotal, data not shown).

Excess lions were removed through translocation, euthanasia and hunting. The percentage of lions removed through each of these interventions over time is shown in Fig. 7. Artificial emigration (i.e. translocation by managers) was initiated two to five years after introduction on most reserves (Table 1). The average age at which excess subadult females were removed was 27.4 months (S.D. = 19.8 months, $n=109$ ) and for males it was 26.9 months (S.D. $=11.5$ months, $n=130$ ). The average number of lions removed from each reserve per year varied from 0.2 to 7.5 individuals (Table 1 ). Translocations played a large role in the mid1990 s to early 2000s, but euthanasia and hunting have been increasingly used as means of population control during the last decade (Fig. 7). Removal of lions appeared to be the main factor keeping lion numbers in check in small reserves.

\section{Lion density}

The average density of lions was maintained below 0.22 lion $/ \mathrm{km}^{2}$. Madjuma GR was by far the exception, maintaining a very high average density of 0.56 lion $/ \mathrm{km}^{2}$ (Fig. 8A). Overall, there was no correlation between lion density and reserve area 


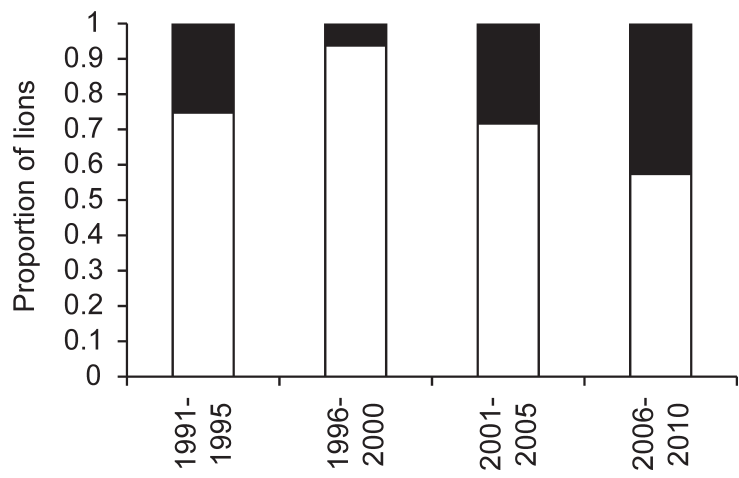

Fig. 7. Methods of removal of 'excess' lions from small reserves in South Africa over time. Open bars indicate translocation; closed bars indicate euthanasia and hunting.

(Fig. 8A; linear regression, $F_{(1,12)}=0.512, P=$ $0.174)$, age of first reproduction of the lionesses (Fig. 8B; linear regression, $\left.F_{(1,58)}=1.81, P=0.184\right)$, litter size (Fig. 8C; linear regression, $F_{(1,224)}=1.71$, $P=0.192$ ), or any other factors tested (data not shown).

In large open systems lion numbers tend to be stable over long periods of time: Kruger NP (Ferreira \& Funston 2010), Kgalagadi Transfrontier Park (Mills et al. 1978; Castley et al. 2002; Funston 2011) and Etosha NP (Stander 1991; P.J. Funston, unpubl. data), or for intermittent but extended time periods (Serengeti NP: Packer et al. 2005). This stability suggests that lion population growth in the wild is regulated through natural processes. Population growth rates of lions in small reserves in South Africa that we studied were high for the first three to five years following introduction. Once a desired number of lions was reached, managers effectively controlled the growth rates at near zero levels, mostly through the removal of subadults. When comparing these population processes with lions studied in more open systems they most closely matched the parameters recorded in Nairobi NP, Kenya (Rudnai 1973). Nairobi NP is not all that large $\left(117 \mathrm{~km}^{2}\right)$ and at that time was largely unfenced, but was part of the Athi-Kaupitiei ecosystem extending over $2200 \mathrm{~km}^{2}$, with an annual migration of ungulates into and out of the reserve. As has also been found in the migratory Serengeti NP system, this necessitated that subadult lions emigrated at a young age (Pusey \& Packer 1987). Thus in both the South African small reserves and Nairobi NP population numbers were constant and emigration rates (both natural and simulated) were high.

Kettles \& Slotow (2009) noted that the market for live translocations of lions had petered out by the mid-2000s with an oversupply and a decline in the number of new reserves reintroducing lions, and this continues to be the case. Prior to this, managers simulated dispersal of subadults through translocation with minimal need for hunting or euthanasia. Managers then continued simulating subadult dispersal by increasing lethal removal (euthanasia or hunting) to replace translocation. As an extreme example of the levels of culling in recent years, Madikwe GR culled its lion population down from over 110 individuals in 2009, to just 40 individuals in 2012 (D. Hofmeyr, pers. comm. 2012). Even without this extreme case, if we take the 700 lions in small reserves today and continue with current management practices, there would be an excess of about 90 lions per year available for translocation, or to be euthanased in South Africa each year. Clearly then, a shift in management approach is required to reduce the number of excess lions produced as this is becoming an ethical dilemma.

Mimicking of open system parameters has been proposed as a more ethical way to manage lion population growth (Miller et al. 2013; Ferreira \& Hofmeyr 2014). Two open systems have been extensively studied that could serve as models, namely Kruger NP and Serengeti NP (Table 2). Kruger NP had an older age of first reproduction and longer inter-birth intervals than all the other systems studied, while Serengeti NP had smaller litters and a lower cub survival (Table 2). Kruger NP is typically savanna habitat without mass prey migrations, while most of the lion research in the Serengeti ecosystem has been done in open plains with migratory prey (Mills \& Funston 2003), so the Kruger NP system may be more applicable to small reserves, which are typically savanna habitat and do not have any prey migration. 

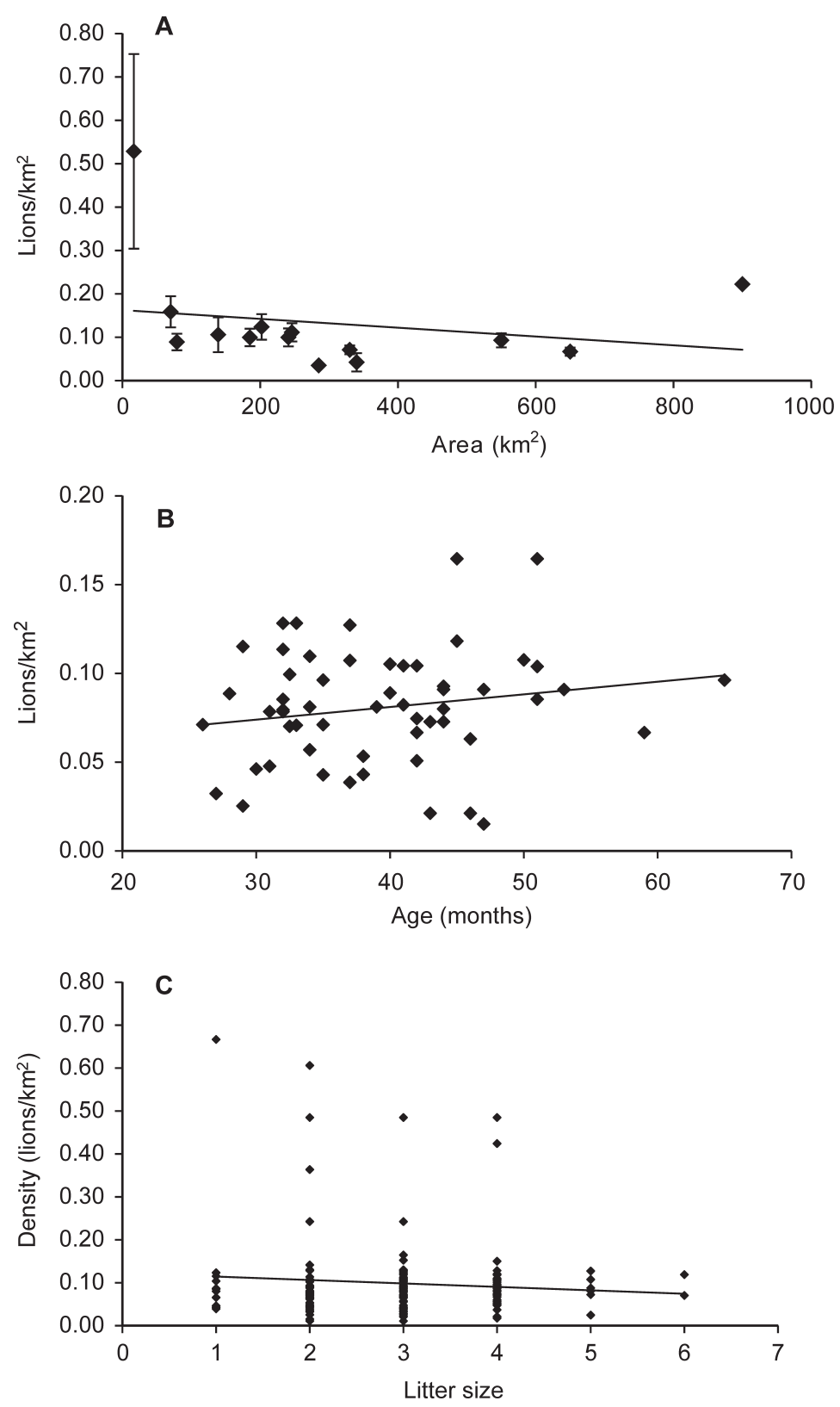

Fig. 8. Lion density in small reserves in South Africa compared to $(\mathbf{A})$ area of reserve (14 reserves; linear regression, $\left.F_{1,12}=0.512, P=0.488\right)(B)$ age of lionesses at first reproduction $(n=59$ lionesses in 10 reserves; linear regression; $\left.F_{1,58}=1.89, P=0.174\right)$, and $(\mathbf{C})$ litter size $\left(n=226\right.$ litters from 99 lionesses in 13 reserves; linear regression, $F_{1,224}=$ $1.71, P=0.192)$.

However, we present both approaches here for managers to consider.

\section{Kruger NP approach}

Increasing the age of first reproduction of females and increasing inter-birth intervals could be achieved through chemical contraception. This would likely be necessary in the long term and not just during start-up phases. Killian (2003) suggested that short inter-birth intervals might be limited to start-up populations (as a result of low density) and Hunter (1998) suggested that young ages of 
first reproduction may also be limited to start-up populations. However, our data have shown that these phenomena were not limited to start-up populations and thus must be considered possible at all times. The limited data on ad hoc contraception in the past showed that contraception has been effective at lengthening inter-birth intervals, thus this approach shows promise. The pros and cons of chemical contraception are discussed in Miller et al. (2013).

\section{Serengeti NP approach}

Litter sizes were smaller in Serengeti NP (Table 2). A reduction in litter size could be achieved with surgery. Unilateral tubal salpingectomy, unilateral hysterectomy or unilateral ovario-hysterectomy are being explored as explained in Miller et al. (2013). Cub survival rates were low in Serengeti NP, due mainly to seasonally low prey availability and high levels of infanticide (Packer et al. 1988). In all other reserves cub survival rates were relatively high (Funston 2011; Table 2), and particularly on the small South African reserves, infanticide rates were low. As there was no prey migration and limited competition in small reserves, it is unlikely that either of these factors would be affected if subadult removal were reduced. Selective culling of cubs to reduce cub survival is an option being explored by the LiMF (Miller et al. 2013). Both reducing the number of cubs born and reducing cub survival would help reduce the number of females reaching reproductive age and thus reduce population growth rates.

There is evidence from Addo Elephant NP that introducing spotted hyaenas (Crocuta crocuta) and skewing the male:female adult ratio in favour of males increased natural cub mortality in the early years following reintroduction (Hayward et al. $2007 a, b)$. There was, however, no infanticide observed on Addo after the initial start-up years, even though the adult male:female ratio was maintained, and only a handful of other instances of infanticide on other reserves. In fact a further introduction of males to Addo Elephant Park in later years did not result in any infanticide suggesting that it is not a viable option for population control (Tambling et al., in press) although it would still be useful from a genetic standpoint.

It may also be useful to completely sterilize a few lionesses to reduce growth rates in combination with the above-suggested approaches. Selati GR, which had lions with the lowest reproductive rate and thus almost no excess lions of the reserves studied here, used sterilization and some hunting in their management approach. One of the potential problems with sterilization is that it cannot be reversed, which in certain circumstances could be problematic when a population increase is required. Selati GR experienced this when half of their lions were killed in snares, leaving no reproductively active lionesses and forcing them to bring in new lionesses (I. Bester, pers. comm. 2012). Furthermore, sterilization raises serious ethical concerns, especially if it is used on females that have not reproduced prior to sterilization. Thus sterilization should be used very cautiously and probably not as the principal means of population control as it cannot be reversed. If it is to be used, it would be better to sterilize females that have already successfully raised cubs so as not to completely negate their reproductive potential.

The ethics of the above suggestions must be carefully considered. Contraception would reduce a female's reproductive potential, but would also reduce the number of animals requiring euthanasia at a later stage (where currently many are euthanased before they have reached reproductive age). Surgery to reduce litter sizes would also reduce a female's reproductive potential, however as above, it should reduce the number of euthanased animals overall. The ethics surrounding the killing of cubs to mimic lower cub survival rates would likely preclude using this technique routinely. Managers will need to find a balance that maximizes reproductive potential while minimizing euthanasia.

The majority of male tenure lengths were dictated by management through removal of males and not natural processes. This was true not only for reserves with only one pride, but also for those with more than one pride. Managers often limited the number of adult males, resulting in little or no competition for tenure. As a result tenure length of males was typically much higher on the small South African reserves (up to 10 years) than on any of the larger more open systems (typically less than two years in Serengeti and Kruger NPs; Packer et al. 1988; Funston et al.2003). While it did not have much influence on reproductive rates, there were a few incidents where induced (artificial) takeovers shortened inter-birth intervals and possibly also reduced the age of first reproduction for a few lionesses. Therefore, managers should carefully consider the timing when inducing takeovers (i.e. new males should not be introduced to a pride when there are cubs $>12$ months old but still 
dependent on the lionesses), and could contracept some of the lionesses at the time of takeover to avoid localized population explosions.

More importantly, shorter male tenure length may be essential for maintaining higher levels of genetic variability. For example, in Madiwke GR only four lineages were reintroduced, founder males were related to founder females and since 1997 only one male lineage maintained tenure for nine years, resulting in breeding with direct relatives (Trinkel et al. 2010). Thus managers should consider reducing tenure lengths of males on reserves to mimic a more natural turnover rate and while this may not have much effect on growth rates, it should result in genetically more diverse populations and would thus more closely mimic natural populations.

Managing lions in fenced reserves is expensive (Packer et al. 2013) and the costs associated with the above suggestions would be substantial. Each reserve must determine which method(s) are most suited to reach their management goals while maintaining their ethical principles and staying within their financial constraints. On reserves where hunting is not prohibited, ethical management hunts could be a useful source of income for the reserve.

In conclusion, it is clear that most managers of reintroduced lions in small reserves in South Africa are using (simulating) very few of the mechanisms that limit the reproductive rate of lions in larger, more open systems. By largely avoiding systematic contraception to induce these effects, and focussing more on the removal of excess lions, the situation has developed where there is no longer much opportunity for the translocation of lions to new areas (Kettles \& Slotow 2009) and where euthanasia has become a vital management option. Furthermore this approach has led to high levels of inbreeding (Trinkel et al. 2008, 2010) and seriously questions the conservation value (Slotow \& Hunter 2009) of the over 700 lions involved. The first step to remedy this situation would be for managers to use one of the approaches outlined above to reduce population growth, with preference to the Kruger NP approach due to ecological similarities. This will not, however, address the genetic degradation of the various populations. We argue, therefore, that the further step would be to develop an integrated plan to manage the movement of lions between respective reserves, not with the aim of controlling population sizes, but to maintain the maximum amount of genetic diversity within the overall population. This process has been started by LiMF (Miller et al. 2013).

\section{ACKNOWLEDGEMENTS}

We thank everyone who has contributed data to this project: Rob Slotow for access to the raw data regarding lion reintroductions used in his publication Slotow \& Hunter (2009) and for data from Pilanesberg NP and Madikwe GR; Cailey Owens and Monika Ogden of K.e.r.i., Global Vision International (GVI) staff and volunteers, in particular Peter Bradford, Sophie Neimann and Kobus Havermann for data from Karongwe GR; Warwick Davis-Mostert and GVI for DeBeers VenetiaLimpopo NR data; lan Bester and LEO (especially Sophie Niemann) for Selati GR data; Mike Pieterse at Thornybush NR; Andre Burger and Dave Powrie at Welgevonden PGR; Simon Morgan and Michelle Swemmer from Wildlife ACT for Thanda PGR data; Tarik Bodasing and Simon Morgan for Tembe Elephant Park data; Audrey Delsink and Ross Kettles for Greater Makalali PGR data; Simon Naylor and Tarryne Burke for Mun-ya-wana PNR data; Charlene Bissett, Angus SholtoDouglas and the staff for Kwandwe PGR data; Patrick Darcis of Mabula GR for Madjuma data; Craig Tambling for Addo Elephant NP data (with some clarification from Matt Hayward) and John O'Brien for Shamwari Game Reserve data. We also thank Matt Hayward, one anonymous reviewer and Emmanuel Do Linh San for constructive comments on an earlier draft of the manuscript.

\section{REFERENCES}

BERTRAM, B.C. 1975. Social factors influencing reproduction in wild lions. J. Zool. 177: 463-482.

CASTLEY, J.G., KNIGHT, M.H., MILLS, M.G.L. \& THOULESS, C. 2002. Estimation of the lion (Panthera leo) population in the southwestern Kgalagadi Transfrontier Park using a capturerecapture survey. Afr. Zool. 37: 27-34.

DRUCE, D., GENIS, H., BRAAK, J., GREATWOOD, S., DELSINK, A., KETTLES, R., HUNTER, L. \& SLOTOW, R. 2004. Prey selection by a reintroduced lion population in the Greater Makalali Conservancy, South Africa. Afr. Zool. 39: 273-284.

FERREIRA, S.M. \& FUNSTON, P.J. 2010. Estimating lion population variables: prey and disease effects in Kruger National Park, South Africa. Wildl. Res. 37: 194-206.

FERREIRA, S.M. \& HOFMEYR, M. 2014. Managing charismatic carnivores in small areas: large felids in South Africa. S. Afr. J. Wildl. Res. 44: 32-42.

FUNSTON, P.J. 2008. Conservation and management of lions in Southern Africa: status, threats, utilization and the restoration option. In: B. Croes, H.H. Delongh 
\& H. Bauer (Eds), Management and conservation of large carnivores in West and Central Africa (pp. 109-131). Institute of Environmental Sciences, Leiden.

FUNSTON, P.J. 2011 Population characteristics of lions (Panthera leo) in the Kgalagadi Transfrontier Park. S. Afr. J. Wildl. Res. 41: 1-10.

FUNSTON, P.J., MILLS, M.G.L., RICHARDSON, P.R.K. \& VAN JAARSVELD, A.S. 2003. Reduced dispersal and opportunistic territory acquisition in male lions (Panthera leo). J. Zool. 259: 131-142.

GRANGE, S., OWEN-SMITH, N., GAILLARD, J-M., DRUCE, D.J., MOLEÓN, M. \& MGOBOZI, M. 2012. Changes of population trends and mortality patterns in response to the reintroduction of large predators: the case study of African ungulates. Acta Oecol. 42: 16-29.

HANBY, J.P. \& BYGOTT, J.D. 1979. Populations changes in lions and other predators. In: A. Sinclair \& $M$. Norton-Griffiths (Eds), Serengeti: dynamics of an ecosystem (pp. 249-262). University of Chicago Press, Chicago.

HAYWARD, M.W., ADENDORFF, J., O'BRIEN, J., SHOLTO-DOUGLAS, A., BISSETT, C., MOOLMAN, L.C., BEAN, P., FOGARTY, A., HOWARTH, D., SLATER, R. \& KERLEY, G.I.H. 2007a. Practical considerations for the reintroduction of large, terrestrial, mammalian predators based on reintroductions to South Africa's Eastern Cape Province. Open Conserv. Biol. J. 1: 1-11.

HAYWARD, M.W., ADENDORFF, J., O'BRIEN, J., SHOLTO-DOUGLAS, A., BISSETT, C., MOOLMAN, L.C., BEAN, P., FOGARTY, A., HOWARTH, D., SLATER, R. \& KERLEY, G.I.H. 2007b. The reintroduction of large carnivores to the Eastern Cape, South Africa: an assessment. Oryx 41: 205-214.

HAYWARD, M. \& KERLEY, G. 2009. Fencing for conservation: restriction of evolutionary potential or a riposte to threatening processes? Biol. Conserv. 142: 1-13.

HUNTER, L.T.B. 1998. The behavioural ecology of reintroduced lions and cheetahs in the Phinda Resource Reserve, KwaZulu-Natal, South Africa. Ph.D. thesis, University of Pretoria, Pretoria.

HUNTER, L.T.B., PRETORIUS, K., CARLISLE, L.C., RICKELTON, M., WALKER, C., SLOTOW, R. \& SKINNER, J.D. 2007. Restoring lions Panthera leo to northern KwaZulu-Natal, South Africa: short-term biological and technical success but equivocal long-term conservation. Oryx 41: 196-204.

KETTLES, R. \& SLOTOW, R. 2009. Management of free-ranging lions on an enclosed game reserve. S. Afr. J. Wildl. Res. 39: 23-33.

KILIAN, P.J. 2003. The ecology of reintroduced lions on the Welgevonden Private Game Reserve, Waterberg. M.Sc. thesis, University of Pretoria, Pretoria.

LEHMANN, M.B., FUNSTON, P.J., OWEN, C.R. \& SLOTOW, R. 2008. Reproductive biology of a pride of lions on Karongwe Game Reserve, South Africa. Afr. Zool. 43: 230-236.

MILLER, S.M., BISSETT, C., BURGER, A., COURTENAY, B., DICKERSON, T., DRUCE, D.J., FERREIRA, S., FUNSTON, P.J., HOFMEYR, D., KILIAN, P.J., MATTHEWS, W., NAYLOR, S.,
PARKER, D.M., SLOTOW, R., TOFT, M. \& ZIMMERMANN, D. 2013. Management of reintroduced lions in small, fenced reserves in South Africa: an assessment and guidelines. S. Afr. J. Wildl. Res. 43: 138154.

MILLS, M.G.L. \& FUNSTON, P.J. Large carnivores and savanna heterogeneity. In: H.C. Biggs, J.T. du Toit \& A.R.E. Sinclair (Eds), The Kruger experience: ecology and management of savannah heterogeneity (pp. 370-388). Island Press, Washington.

MILLS, M.G.L., WOLFF, P., LE RICHE, E.A.N. \& MEYER, I.J. 1978. Some population characteristics of the lion Panthera leo in the Kalahari Gemsbok National Park. Koedoe 21: 163-171.

NOWELL, K. \& JACKSON, P. 1996. Wild cats: status survey and conservation action plan. IUCN. Gland, Switzerland.

PACKER, C., HERBST, L., PUSEY, A.E., BYGOTT, J.D., HANBY, J.P., CAIRNS, S.J. \& BORGERHOFF MULDER, M. 1988. Reproductive success of lions. In: T.H. Clutton-Brock (Ed.), Reproductive success studies of individual variation in contrasting breeding systems (pp. 363-383). University of Chicago Press, Chicago and London.

PACKER, C., HILBORN, R., MOSSER, A., KISSUI, B., BORNER, M., HOPCRAFT, G., WILMSHURST, J., MDUMA, S. \& SINCLAIR, A.R.E. 2005. Ecological change, group territoriality, and population dynamics in Serengeti lions. Science 307: 390-393.

PUSEY, A.E. \& PACKER, C. 1987. The evolution of sexbiased dispersal in lions. Behaviour 101: 275-310.

RUDNAI, J. 1973. Reproductive biology of lions (Panthera leo massaica Neumann) in Nairobi National Park. E. Afr. Wildl. J. 11: 241-253.

SCHALLER, G.B. 1972. The Serengeti lion. University of Chicago Press, Chicago.

SKINNER, J.D. \& CHIMIMBA, C.T. 2005. The mammals of the southern African subregion (5th edn). Cambridge University Press, Cape Town.

SLOTOW, R. \& HUNTER, L.T.B. 2009. Reintroduction decisions taken at the incorrect social scale devalue their conservation contribution: the African lion in South Africa. In: M.W. Hayward \& M.J. Somers (Eds), Reintroduction of top-order predators (pp. 41-73). Wiley-Blackwell, Oxford.

SMUTS, G.L., HANKS, J. \& WHYTE, I.J. 1978. Reproduction and social organisation of lions from the Kruger National Park. Carnivore 1: 17-28.

STANDER, P.E. 1991. Demography of lions in the Etosha National Park, Namibia. Madoqua 18: 1-9.

TRINKEL, M., FERGUSON, N., REID, A., REID, C., SOMERS, M., TURELLI, L., GRAF, J., SZYKMAN, M., COOPER, D., HAVERMAN, P., KASTBERGER, G., PACKER, C. \& SLOTOW, R. 2008. Translocating lions into an inbred lion population in the HluhluweiMfolozi Park, South Africa. Anim. Conserv. 11: 138-143.

TRINKEL, M., FUNSTON, P., HOFMEYR, M., HOFMEYR, D., DELL, S., PACKER, C. \& SLOTOW, R. 2010. Inbreeding and density-dependent population growth in a small, isolated lion population. Anim. Conserv. 13: 374-382 